\title{
Cooperação e integração regional em saúde na América do Sul: a contribuição da Unasul-Saúde
}

\author{
Regional cooperation and integration in health in South America: \\ the contribution of Unasur-H ealth
}

Paulo M archiori Buss ${ }^{1}$ JoséRoberto Ferreira ${ }^{1}$
${ }^{1}$ Centro de Relações Internacionais, Fundação Oswaldo Cruz. Av. Brasil 4365, $M$ anguinhos. 21040-900 Rio de Janeiro RJ.buss@fiocruz.br
Abstract The scope of this study is to discuss the process of integration of South America in the domain of health, from the constitution of the Union of South American Nations (U nasur), in M ay 2008, through to the emergence of the Unasur Council of $\mathrm{H}$ ealth, in 2009, and its ongoing development in the past year (2009-2010). This study is descriptive in nature and the medium of investigation was the case study. The authors present themain constituent elements of theSouthAmerican $\mathrm{H}$ ealth Agenda, with particular emphasison thearea of development and management of human resources in health, which was coordinated by Brazil in the past year. The authors conclude that this interchange will contributeto minimization of the asymmetries amongst the countries, collaborating to improve the quality of life and health conditions in the region.

Key words Union of South American Nations, South American health agenda, $M$ anagement of human resources in health
Resumo 0 objetivo desteartigo édiscutir o processo de integração da América do Sul na área da saúde, desde a constituição da União de $\mathrm{N}$ ações Sul-Americanas (Unasul), em maio de 2008, até o surgimento do Consel ho de Saúde da Unasul, em 2009, e seu ulterior desenvolvimento no último ano (2009-2010). Esteestudo é de caráter descritivo e o meio de investigação foi o estudo de caso. A presentam-se os principais el ementos constitutivos da Agenda deSaúdeSul-Americana, com especial destaque para a área de desenvolvimento egestão de recursos humanos em saúde, queesteve sob a coordenação do Brasil no último ano. Os autores concluem que esse intercâmbio contribuirá para minimizar as assi metrias entre os países, colaborando para a melhoria das condições de vida e saúde da região.

Palavras-chave U nião denações sul-americanas, Agenda de saúde sul-americana, G estão de recursos humanos em saúde 


\section{Introdução}

Em dezembro de 2009, os Chefes de Estado da recém-criada União de Nações Sul-Americanas (Unasul) instituíram o Conselho de Saúde SulAmericano (Unasul-Saúde). Discutir o significado deste ato político e suas possíveis implicações com a cooperação em saúde na América do Sul é o objetivo central deste artigo. Para fazêlo, serão analisados al guns caminhos do processo re cente de integração da região, a constituição da Unasul em 2008 eos desdobramentos do primeiro ano de existência da Unasul-Saúde (abril de 2009 a abril de 2010).

\section{Antecedentes}

As ideias de integração regional da América do Sul remontam aos movimentos de independência que tiveram lugar na região desde o final do século XVII, culminando com as independências das então colônias espanholas e portuguesa nas Américas, entre 1804 e 1824.

O Brasil manteve sua integridade territorial graças à concentração de poder na etapa colonial e sua permanência na sequência familiar do Império, enquanto a força à afirmação dos vice-reinados do lado hispânico levou ao abandono do sonho de Simon Bolívar e consolidou a divisão política da região. N esse quadro, a limitação imposta pel os obstácul os geográficos (os Andes, florestas e grandes rios) restringiu a comunicação com o mundo exterior ao acesso transoceânico, seja pel o Atlântico, para o Brasil, Argentina, Uruguai eVenezuela, ou pelo Pacífico para os demais países hispânicos, limitando as relações políticoeconômicas das colônias e, mesmo mais tarde, das nações independentes delas resultantes.

Além da vulnerabilidade econômica gerada pela exploração do sistema colonial, que impediu o desenvolvimento das forças produtivas e gerou a concentração em atividades primárias, extrativas e agrícolas, a situação geográfica da América do Sul reduziu a partici pação efetiva da região no comércio mundial, que se processava principalmenteno hemisfério norte, condicionando sua relativa marginalidade. A fragmentação dos Estados, obrigando a articulação isolada de cada um com as potências externas, reduziu ainda mais a possibilidade de crescimento econômico e manteveo subdesenvolvimento da região. 0 relacionamento entre Brasil e os demais países se manteve relativamente distante, reproduzindo de certa maneira a separação histórica entre
Portugal e Espanha, reforçada na América pelas limitações geográficas mencionadas, que predispuseram um bom número de países a viverem "decostas" uns para os outros, deixando deaproveitar o mercado interno na região ${ }^{1}$.

Também deixou deser aproveitada, nesseisolamento recíproco, a riqueza representada pela concentração de recursos estratégicos na região, que inclui a alta disponibilidade de água doce por habitantee seu potencial hidroelétrico; a alta percentagem de área agriculturável; a autossuficiência em petróleo, minerais e metais básicos; a grande biodiversidade animal e vegetal; e, internamente, um mercado potencial latente de bens industriais, que poderia assegurar a expansão industrial independentemente do mercado externo, mais competitivo. Tudo isto tendo em vista a hipótese de inversão de padrão de desenvolvimento, voltado exclusivamente para os centros dinâmicos da economia mundial, que viesse a adotar um padrão de "desenvolvimento para dentro" da própria região².

Tomando em conta iniciativas regionais que vinham sendo promovidas na segunda metade do século passado, como as relativas à Bacia do Prata eà área Andina (ambas em 1969), ea Associação Latino-Americana de Livre Comércio (Alalc), transformada depois em Associação Latino-Americana de Integração (Aladi, nos anos 1980), a Constituição Brasileira ${ }^{3}$ de 1988 , no seu artigo quarto, que trata das relações internacionais do país, incluiu o preceito dequeA República Federativa do Brasil buscará a integração econômica, política social e cultural dos povos da América Latina, visando à formação de uma comunidade latino-americana de $\mathrm{N}$ ações. D essas tentativas, destacam-se as aproximações sub-regionais, como o pacto Andino, mais tarde o Tratado de Cooperação Amazônica (1978) e mais recentemente o M ercado Comum do Sul (M ercosul) (1991), reforçando uma visão mais escalonada da integração sul-americana, ainda assim aproveitando a vantagem comparativa que oferece a região por concentrar recursos considerados estratégicos em todo o mundo.

O M ercosul nasceu da mudança qualitativa no relacionamento entre o Brasil e a Argentina a partir do início dos anos oitenta ese desenvolveu à luz das instituições democráticas, da estabilização econômica eda sua crescentearticulação com o sistema internacional. Depois de sua formalização, em 1991, com o Tratado deAssunção, evoluiu para a formação de uma união aduaneira, deixando de ser apenas zona de livre comércio e, apesar das crises financeiras que se seguiram, lo- 
grou chegar ao começo do século XXI como iniciativa amadurecida, consolidada eque traz subjacente o papel de mola propulsora da construção do espaço de integração da América do Sul.

N essa evolução, foram superadas diversas controvérsias sobre direitos de soberania territorial entre Argentina e Chile (Canal de Beagle, 1978), entre Equador e Peru (1981, repetida na década seguinte) e o conflito entre Argentina e Inglaterra pela posse das ilhas M alvinas (1982), restando ainda por se resolver a questão da me diterraneidade da Bolívia, a delimitação marítima entre Peru e Chile e diferenças político-ideológicas que mantêm Venezuela e Colômbia. Todos esses problemas constituem importantes desafios que demandam encaminhamento da agenda política da integração sul-americana.

o Presidente Lula, ao instalar seu governo, declarou quea prioridade da política externa se ria a construção de uma América do Sul politicamente estável, próspera e unida, com base nos ideais democráticos e de justiça social ${ }^{4}$. Avançando nesse cometido, ao tratar dos desafios brasileiros, no que chamou de "Era dos Gigantes", Samuel Pinheiro Guimarães ${ }^{5}$, então Secretário Executivo do M inistério de Relações Exteriores, destacou em minuciosa análise o esforço do país em contribuir para a emergência de um mundo multipolar, mais democrático, mais próspero e mais justo, tendo como sua principal prioridade promover a unidade econômica, a integração física e a ação política coordenada dos países da América do Sul no âmbito internacional. Atualmente, tendo Pinheiro Guimarães assumido a Secretaria de Assuntos Estratégicos da Presidência da República, pode-se admitir que esta orientação conte, ainda, com maior apoio.

0 desafio para levar adiante uma proposta dessa magnitude consiste na possibilidade de desenvolvimento de fatores estruturantes relativos à infraestrutura e à política, destacando-se, entre os primeiros, a área de transportes (fluvial, marítimo, ferroviário, rodoviário e aéreo), a integração energética (sobretudo hidroelétrica) ea implantação de um eficiente sistema de comunicações. Será necessário superar a barreira dos Andes, ampliar o aproveitamento do potencial energético em favor de toda a região e assegurar a utilização das telecomunicações através de redes de processamento que interliguem o grande número de computadores da região e permitam, entre outros, um maior progresso dos sistemas educativos e de desenvolvimento tecnológico.
$\mathrm{Na}$ área política, o interesse dos Estados é garantir a melhoria crescente do bem-estar de suas populações e a segurança de seus territórios, estabelecendo negociações que definam a estrutura jurídica do sistema internacional e os diversos aspectos das relações entre Estados, indivíduos e empresas, incluindo as normas relativas ao comércio, investimentos, capitais, meio ambiente, questões militares, manutenção da qualidade de vida e movimentos do trabalho, entre outros ${ }^{5}$. Nesse contexto, vêm se consolidando os rumos políticos do processo de integração da região, que fomentaram a concepção da Unasul, destacando os direitos humanos, ao regime democrático, ao princípio da não intervenção, de solidariedade e justiça social.

N essas duas vertentes repousa o processo de desenvolvimento da região, dirigido a uma crescenteinteração política eeconômica, com aumento da produção e da produtividade e melhores combinações de processos produtivos, ampliando o mercado de trabalho mas, também, assegurando a melhora significativa das condições de vida da maioria da população, os direitos de soberania territorial dos Estados Nacionais e uma forte presença política da região no âmbito internacional.

Sintetizando a visão positiva da diplomacia brasileira quanto a Unasul, Simões ${ }^{2}$ afirma quea U nasul inaugura uma fase sem precedentes nas relações internacionais na América do Sul [...], representando uma "mudança de paradigma" no relacionamento sul-americano [...], oportunidade real de aceleração dos desenvolvimentos econômico esocial dos países membros e possibilidade concreta de maior projeção internacional da região num mundo multipolar.

No caso brasileiro, a análise dos discursos e das articulações endossadas pelos formuladores da política externa nacional demonstra que a América do Sul está cada vez mais presentecomo referência regional do país. A região passou a incluir, para além do discurso e retórica diplomáticos, também ações concretas, que ganham gradativamente espaço e relevância na agenda nacional.

0 importante é que se faça uma escolha adequada do model o deregionalização, que propicie a construção decoesão interna por meio do reconhecimento mútuo de todos os países da região como partícipes deuma mesma unidade, a proje ção extrarregional vantajosa e a percepção de tal unicidade por parte dos atores internacionais. 


\section{A constituição da Unasul}

A experiência acumulada pelos esforços deaproximação regional, aprimorando o diálogo diplomático e as formas mais variadas de intercâmbio e colaboração nos campos político, econômico, social e cultural, permitiu avançar para a mais nova e ampla iniciativa político-estratégica de relacionamento sul-americano, com o lançamento da União deN ações Sul-Americanas (Unasul), oficializado em 23 demaio de 2008, em Brasília. Reunindo os doze países independentes da região, tem como objetivo construir, de forma participativa e consensual, um espaço de integração e união nos campos cultural, social, econômico e político entre seus povos, outorgando prioridade ao diálogo político, às políticas sociais, saúde, educação, energia, infra-estrutura, financiamento e meio ambiente, entre outros, com vistas a eliminar as desigualdades sócio-econômicas, lograr a inclusão social ea participação cidadã, fortalecer a democracia e reduzir as assimetrias, no marco do fortalecimento da soberania e independência dos Estados membros ${ }^{6}$. No Quadro 1, apresentam-se as principais características estruturais e funcionais da Unasul.

Neste contexto, a diplomacia regional tem 0 mandato de identificar as oportunidades e negociar os acordos nas áreas estruturantes que representem maior prioridade e sejam passíveis de intervenções positivas, incluindo as áreas de Defesa e de Saúde.

A emergência da Unasul não éum evento fortuito; ao contrário, é precedida de muitos antecedentes importantes, como se apontou.

A constituição da Unasul ocorre num momento de reafirmação democrática e de emergência de governos populares na maioria dos países da região. 0 Brasil, mantendo limites territoriais com quase todos os países da América do Sul, com exceção de Chile e Equador, com aproximadamente a metade da área territorial, da população e do Produto Interno Bruto (PIB) da região, com o parque industrial maior e mais diversificado e com sua tradição de não intervenção, situa-se numa posição ímpar para de fender e respaldar a integração pretendida, promovendo o desenvolvimento, não só com a oferta de cooperação nas áreas em que lograram meIhor desempenho, como com a realização de investimentos produtivos, visando aumentar a produção com valor agregado, ampliar a exportação e gerar mais renda e empregos na região como um todo.

Contudo, em absoluto o processo de integração na América do Sul tem sido destituído de conflitos internos aos países ou entre as nações participantes. No front interno da maioria dos

Quadro 1. A União das N ações Sul-Americanas (Unasul).

Os doze países que compõem a América do Sul - Argentina, Bolívia, Brasil, Chile, Colômbia, Equador, Guiana, Paraguai, Peru, Suriname, Uruguai e Venezuela - ocupam um território de 17,8 milhões de $\mathrm{km}^{2}$, têm milhares de quilômetros de fronteiras compartilhadas e abrigam 385 milhões de pessoas (dados de 2008).

A União das Nações da América do Sul (U nasul), em espanhol, la Unión de Naciones Sudamericanas (U nasur), é uma união intergovernamental que integra duas uniões alfandegárias preexistentes: Mercosul e Comunidade Andina (CAN). É parte de um processo permanente de integração da América do Sul. 0 Tratado Constitutivo foi assinado em 23 de maio de 2008, em Braślia, Brasil, pelos doze chefes de Estado. Segue o modelo da União Européia.

A Unasul estrutura-se com os seguintes componentes de poder:

- O Conselho dos Chefes de Estados e Governo é a instância política mais elevada;

. 0 Conselho de Ministros das Relações Exteriores formula propostas submetidas à decisão do

Conselho e toma as decisões executivas;

- O Conselho dos Delegados compõe-se de funcionários governamentais de alto nível dedicados a organizar o trabalho dos dois Conselhos acima mencionados e a implementar suas decisões;

- Conta ainda com os Conselhos Sul-Americanos da Defesa, Saúde, Desenvolvimento Social, e de Educação, Cultura, Ciência, Tecnologia e Inovação.

A sede da União localiza-se em Quito, Equador, onde está também a Secretaria Geral; o Parlamento da América do Sul situa-se em Cochabamba, Bolívia; e o banco regional, Banco do Sul, será sediado em Caracas, Venezuela.

A Presidência Pro Tempore (PPP) é ocupada por um ano e alterna entre os Estados-membros. Entre julho de 2009 e julho de 2010, a PPT da U nasul esteve a cargo do Equador e passou à Guiana. 
países, a Unasul éainda um projeto de governos, com reduzido conhecimento por parte das populações nacionais ${ }^{7}$. De outro lado, para outros analistas, as enormes desproporções econômicas e as diferenças culturais, sociais e políticoideológicas, além deconflitos territoriais históricos, estariam na raiz das dificuldades existentes entre os países para a consecução do projeto de integração sul-americana. A política de integração envidada pelo Brasil, por exemplo, é vista frequentemente como "imperialista", isto é, o Brasil estaria disposto a promover uma política de expansão e de domínio territorial, cultural e econômico e de defender uma integração baseada principal mente nos interesses do empresariado brasileiro ${ }^{8-10}$, representados pelo agronegó$\mathrm{Cio}^{11}$, por projetos de infraestrutura ${ }^{12}$ e pela presença militar ${ }^{13}$ e não numa agenda de realização de direitos ${ }^{8}$. A Alternativa Bolivariana para os Povos da Nossa América (Alba), da qual participam apenas três dos doze países sul-americanos (Bolívia, Equador eVenezuela), propõe a criação de uma estrutura monetária regional, o Sistema Unitário de Compensação Regional (Sucre), que, segundo Cassen $^{14}$, em resposta ao liberalismo quebraria o monopólio do Fundo Monetário Internacional (FMI). Todavia, não conta com o apoio dos demais países que discutem exclusivamente a ampliação do uso de moedas nacionais nos negóciosinternacionais dentro do bloco ${ }^{15}$. Já a implantação do Banco do Sul, importante estrutura da Unasul, cuja criação está decidida pelos dirigentes do bloco, avança lentamente devido às resistências levantadas pelo Brasil ${ }^{14}$.

A despeito dos conflitos mencionados, a Unasul veio a se implantar politicamente, com a base de que num mundo cada vez mais globalizado e regionalizado, a constituição de organismos regionais amplos, comprometidos com o desenvolvimento de cada país e da região como um todo, com clamores de equidade, dá o tom dos entendimentos multilaterais vigentesnesteinício desé culo XXI. A Unasul foi o primeiro tratado entre todos os países independentes da América do Sul e somente por eles. É uma nova entidade que emerge para dar à região o contorno político que irá unificar os esforços integracional istas efortificar a identidade internacional daAmérica do Sul ${ }^{16}$.

\section{Antecedentes da integração em saúde}

Astrêsiniciativas preexistentes deintegração sulamericana ( $M$ ercosul, Comunidade Andina e Organização do Tratado da Cooperação Ama- zônica (OTCA) (Quadro 2) já possuíam cooperação em saúde mais ou menos estruturada antes mesmo do surgimento da Unasul.

Asreuniões quederam origem àUnasul-Saúde tomaram em conta as agendas dos entes citados para a construção da Agenda Sul-americana da Saúde e, em última instância, da Unasul-Saúde. Entretanto, o M ercosul e a Unasul são modelos de integração diferentes, com origens distintas; enquanto a Unasul éum processo eminentementepolítico no quediz respeito ao diálogo entreos países da América do Sul, o M ercosul, que teve origens primordialmente comerciais, desenvolveu, ao longo do tempo, viés de concertação política, que passou a incluir temas sociais ${ }^{19}$. 0 Subgrupo de Trabalho n 11-Saúde (SGT-11) do M ercosul e as demais instâncias do Bloco que lidam com temas de saúde, como a Reunião de M inistros da Saúde (RMS), diferem consideravelmente do Consel ho de Saúde da Unasul, pois as decisões têm caráter vinculante ${ }^{20}$.

De outro lado, deve-se registrar o documento recentemente preparado pela Secretaria Permanente do Sistema Econômico da América Latina (SELA) ${ }^{21}$, no qual são analisadas experiências de cooperação em saúde desenvolvidas nos diversos órgãos de integração sub-regional na América Latina e Caribe, como o Sistema de Integração Centro-Americano (SICA), a Comunidade Andina (CAN), a Comunidade do Caribe (Caricom) e M ercosul, além de Alba, Projeto M esoamérica e Unasul.

\section{A emergência da Unasul-Saúde}

A Reunião de Chefes de Estado da Unasul, realizada na Costa do Sauípe, Bahia, Brasil, em de zembro de 2008, criou o Conselho de Saúde SulAmericano22, como órgão de consulta e cooperação em saúde da Unasul. Composto pelos M inistros da Saúde dos doze Estados-membros, a estrutura do Conselho inclui ainda o Comitê de Coordenação, composto dealtos funcionários dos M inistérios; a Secretaria Técnica, ocupada pelo paísque detém a Presidência ProTemporedaUnasul; e Grupos Técnicos (GTs), que se dedicam a desenvolver as cinco áreas prioritárias da Agenda Sul-Americana de Saúde, também definida na mencionada reunião deChefes deEstado de 2008. 0 Conselho estabelece compromissos políticos e orienta o desenvolvimento da Agenda por meio de resoluções e declarações aprovadas nas Reuniões de Ministros, que foram realizadas até aqui em Santiago, no Chile (abril de 2009), Guaiaquil, 
Quadro 2. Três iniciativas preexistentes de integração sul-americana em saúde.

Organismo Andino de Saúde - Convênio Hipólito Unanue (ORAS-CONHU), organismo intergovernamental que pertence ao Sistema Andino de Integração, foi criado pelos M S da Região Andina em 1971 com o propósito de fazer da saúde um espaço para a integração, desenvolver ações coordenadas para enfrentar problemas comuns e contribuir para garantir o direito à saúde. Está dirigido pela Reunião de M inistros da Saúde da Área Andina (REM SAA) e conta com uma Secretaria Executiva permanente estabelecida em 1974 e sediada em Lima, Peru.

O ORAS-CONHU estabeleceu um Plano Estratégico 2009-2012 ${ }^{17}$, que prioriza as seguintes áreas: integração andina esul-americana em saúde, escudo epidemiológico, sistemas de saúde universais, acesso a medicamentos, determinantes sociais da saúde e recursos humanos em saúde.

Mercosul Saúde ${ }^{18}$ - estrutura formada pela Reunião de M inistros da Saúdee SGT 11 Saúde, tem priorizado na agenda regional as discussões em torno de: propriedade intelectual, produção eacesso a medicamentos, determinantes sociais da saúde, sistemas de saúde universais, garantia da inclusão da população nas políticas de saúde, implantação do Regulamento Sanitário I nternacional, vigilância sanitária regional de doenças transmissíveis, política de saúde nas fronteiras, fortalecimento da aten ção primária em saúde política de inovação tecnológica.

Encontra-se entreas prioridades do M ercosul Saúdea harmonização ea homologação denormas nacionais nos segmentos de produtos (medicamentos, vacinas, reativos diagnósticos, farmoquímicos, sanguee hemoderivados, entre outros), atenção à saúde (desenvolvimento e exercício profissional e avaliação euso das tecnologias em serviços de saúde) evigilância em saúde (enfermidades transmissíveis enão transmissíveis).

OTCA - criada em 1978, promove ações conjuntas para o desenvolvimento harmônico da Bacia Amazônica eorganiza seus trabalhos por meio de Comissões, uma das quais a de Saúde (Cesam). A agen da da OTCA inclui as seguintes áreas prioritárias: desenvolvimento de capacidades institucionais; saúdeambiental, incluindo o manejo de recursos hídricos da bacia transfronteiriça do Rio Amazonas; rede de vigilância epidemiológica de enfermidades transmissíveis, com ênfase em malária; desenvolvimento sustentável dos territórios da Amazônia; emelhoria da qualidade de vida eacesso aos serviços desaúdedas populações amazônicas ${ }^{19}$.

no Equador (novembro de 2009), e Cuenca, no Equador (abril de 2010).

A Agenda Sul-Americana de Saúde foi proposta para responder à situação sociossanitária sub-regional ${ }^{21}$ edesdobrou-seoperativamenteno Plano Quinquenal de Saúde 2010-2015 da Unasul, aprovado pelos Ministros em Cuenca, em abril de 2010.

O Plano toma em conta a situação de saúde da América do Sul ${ }^{22}$ e organiza-se em torno de cinco eixos ${ }^{23}$ (Quadro 3).

São centrais na formulação do Plano os princípios de que saúde é um direito fundamental e componente essencial do desenvolvimento, que será integrada aos sistemas nacionais de proteção social e que, por sua ampla aceitação política, constitui-se num importante propulsor da integração das nações componentes da Unasul.

Ele destaca, ainda, que a região conta com capacidades e experiências em saúde que devem ser mobilizadas a favor da integração, visando promover a redução das assimetrias existentes entre os sistemas de saúde, promover a responsabilidade e participação cidadã e o reconheci-
Quadro 3. Eixos do Plano Quinquenal em Saúde da Unasul.

1. Política Sul-americana de Vigilância e Controle de Eventos em Saúde, anteriormente denominado de "escudo epidemiológico sulamericano";

2. Sistemas universais de saúde;

3. Acesso universal a medicamentos e outros insumos para a saúdee desenvolvimento do complexo produtivo da saúdenaAmérica do Sul;

4. Promoção da saúdee ações sobreos determinantes sociais da saúde;

5. Desenvolvimento de recursos humanos em saúde.

mento da saúde como bem público para o conjunto da sociedade. Promove o respeito à diversidade einterculturalidadena implementação de iniciativas de cooperação no campo da saúde, reconhecendo as diferentes realidades nacionais. 
As linhas de ação prioritárias de cada uma das mencionadas áreas foram desenvolvidas por Grupos Técnicos, integrados por representantes dos M inistérios da Saúde dos doze membros da Unasul, sob a coordenação de dois dos países da região.

A Política Sul-Americana deVigilância eControle de Eventos em Saúde, elaborada e imple mentada segundo o Regulamento Sanitário Internacional, tem trabal hado na criação e consolidação da rede sul-americana de vigilância epidemiológica e controle de enfermidades transmissíveis, não transmissíveis e eventos em saúde pública, ambicionando respostas prontas aos problemas de saúde prevalentes na região. Para isto, busca selecionar e padronizar indicadores de morbimortalidade e fatores de risco, assim como criar um sistema de informação para notificação das enfermidades priorizadas, notadamente as emergências de saúde de importância nacional (ESPIN) einternacional (ESPII).

Atuar conjuntamente na vigilância e no controle deenfermidades em áreas defronteiraeidentificar as doenças que devem ser focadas de maneira prioritária (na conjuntura recente, a gripe AH IN 1 ea denguee, a médio prazo, malária, tuberculose, HIV/Aids eoutras doenças emergentes e reemergentes, além das doenças crônicas não transmissíveis prevalentes, estão entre as prioridades da Rede de Vigilância Sul-Americana. Outro componente importante da agenda é o fortalecimento de um Programa Sul-Americano de Imunizações, de forma a al cançar cobertura universal da população com vacinas adequadamenteindicadas pelo perfil epidemiológico vigente.

A cooperação entre os países buscará fortalecer os sistemas nacionais de vigi lância epidemiológica, dotando-os de ferramentas e instrumentos técnico-científicos e gerenciais adequados e mobilizando os recursos nacionais e subcontinentais de diversas fontes e naturezas para tanto.

A políticasul-americana de vigilância defende que as necessidades sanitárias devem sobrepujar os interesses comerciais, garantindo-se 0 acesso oportuno e universal a medicamentos, vacinas e reagentes diagnósticos - entendidos como bens públicos regionais- assim como devem ser facilitados seus processos de produção e transferência de tecnologias, objeto de consideração de outro dos grupos técnicos, que trata do acesso a insumos essenciais para a saúde (ver adiante).

Para responder à complexa situação sociossanitária vigente nos países da região, marcada pela iniquidade no acesso a serviços sociais e de saúde, a segunda prioridade da Agenda Sul-Ame- ricana de Saúde é a construção de "sistemas universais e equitativos de saúde". A perspectiva da cooperação nesta área implica o intercâmbio de experiências e a cooperação quanto à formulação de políticas e legislação condizente com este objetivo, esquemas definanciamento desistemas universais e modelos deatenção, incluindo a atenção primária de saúde e outros níveis de complexidade, assim como a atenção individual ecoletiva. No âmbito de uma iniciativa regional como a Unasul-Saúde, será enfatizado o cuidado especial com a saúde nas fronteiras, incluindo a garantia de portabilidade para 0 acesso aos serviços de saúde de qualquer dos países-membros de sulamericanos não residentes no país em que procuram assistência.

M etodologias de monitoramento e avaliação de universalidade e equidade serão desenvolvidas para aplicação nos âmbitos nacionais e regional. Componente essencial para tanto, será o incremento da participação e controle social dos sistemas de saúde, cujas experiências serão compartilhadas, com vistas à sua implementação nos sistemas nacionais dos países da Unasul.

Obstáculo importante para a universalização do acesso são as limitações dos sistemas de saúde dos países sul-americanos quanto a recursos humanos, tecnológicos e materiais. Além de carecer deestabelecimentos de saúde suficientes eadequados, a região apresenta limitações quanto a medicamentos, vacinas, reagentes diagnósticos, sangue e hemoderivados, equipamentos médico-cirúrgicos e materiais de consumo médicos em ge ral, com a agravante de que boa parte desses insumos não é produzida nos próprios países e eles têm que ser importados a custos elevados para os orçamentos nacionais destinados à saúde.

Assim, o terceiro componente da Agenda propõe que os insumos em saúde a serem consumidos pelos sistemas de saúde sul-americanos sejam preferentemente produzidos pelo Complexo Produtivo da Saúde ${ }^{24}$ no próprio subcontinente. Para tanto, propõe maior articulação públicoprivada em nível regional, garantindo-se a harmonização de políticas industriais e da regulação sanitária de produtos, assim como o enfrentamento de desafios no desenvolvimento de novos produtos, por meio da cooperação em P\&D.

Um banco de preços de medicamentos e a negociação conjunta de preços com fornecedores internacionais, utilizando o poder de barganha do mercado público sul-americano, estão entre as ações do mecanismo regional de garantia de acesso universal a medicamentos a ser implementada na Unasul-Saúde. Uso racional de 
medicamentos, incluindo a harmonização de protocolos oficiais detratamento, com incentivo à prescrição de genéricos produzidos na região, e sistema harmonizado de vigilância e controle de medicamentos, de maneira a garantir acesso a medicamentos seguros, eficazes e de qualidade, também se encontram entre os objetivos do Plano Q uinquenal (PQ).

A quarta área se baseia na importância para a equidade que representa 0 enfrentamento dos determinantes sociais da saúde e a necessidade de combate às iniquidades em saúde por el es ge rada. Para o estabelecimento do programa de ação deste GT, foi tomado em conta o Relatório Final da Comissão da Organização Mundial da Saúde (OMS) sobre Determinantes Sociais da Saúde (DSS) ${ }^{25}$, bem como experiências nacionais da região, como a do Brasil, que criou sua própria Comissão Nacional sobre Determinantes Sociais da Saúde (CNDSS) ${ }^{26}$. Outros governos da América do Sul se interessaram por essa estratégia e, no âmbito da Unasul-Saúde, os ministros propuseram estudar os determinantes sociais em escala regional, através da criação da Comissão Sul-Americana sobre D eterminantes Sociais da Saúde, ou estrutura e/ ou iniciativas eações equivalentes, a serem implantadas pelo grupo responsável por este item da Agenda.

$O$ desenvolvimento demetodologias deavaliação e monitoramento de políticas intersetoriais e participação social, de promoção da saúde e de redução de iniquidades, assim como a incorporação dos temas promoção da saúde e determinantes nos currículos das profissões da saúde, são medidas introduzidas pelo GT no Plano Quinquenal; da mesma forma, mecanismos de comunicação social que garantam o acesso à informação sobre pesquisa em saúde e DSS e projetos multicêntricos deinvestigação sobre políticas públicas orientadas à equidade, intersetorialidade, promoção da saúde, DSS e participação social.

Finalmente, por haver sido entregue à coordenação inicial do Brasil e por seu caráter estraté gico para todas as demais áreas, a quinta área prioritária (desenvolvimento egestão derecursos humanos) será tratada a seguir com detalhes.

\section{Desenvolvimento}

e gestão de recursos humanos em saúde

Os recursos humanos são os agentes fundamentais do setor saúdee, em uma concepção estraté gica, eles não estão "dentro" das organizações, eles "são" as organizações. O bviamente, os re- cursos econômicos e materiais são necessários, mas sua utilização requer a existência de força de trabalho efetiva que articule os diferentes componentes do sistema de saúde.

As reformas setoriais empreen didas na maior parte dos países sul-americanos durante os anos noventa produziram transformações estruturais de caráter regressivo do papel do Estado com a introdução ou aprofundamento de processos de privatização na saúde e com mudanças ideológicas que impactaram substancialmente a força de trabalho em saúde. Além de provocar consequências negativas na qualidade da atenção dos serviços, os processos de reforma setorial produziram o retrocesso de alguns países nos avanços realizados com respeito à atenção primária, e agravaram os problemas já existentes quanto à disponibilidade, distribuição, qualidade na formação e permanência da força de trabal ho, especialmente no setor público.

$\mathrm{Na}$ Agenda de Saúde da U nasul, todos os demais componentes cruzam com a área de recursos humanos deforma matricial edependem dela para seu melhor desempenho. As ações propostas incluem o fortalecimento de condução, liderança, coordenação e gestão, formulação de políticas, capacitação avançada e produção de conhecimento, no campo dos recursos humanos em saúde, e se alinham com os compromissos e acordos regionais subscritos pelos países da América do Sul em âmbito multilateral, entre os quais o Chamado à Ação de Toronto ${ }^{27}$, a Agenda deSaúde para as Américas ${ }^{28,29}$ e o Plano Regional de Recursos H umanos em Saúde da Região Andina ${ }^{30}$. Nesse marco, a operacionalização do desenvolvimento e gestão de recursos humanos em saúde desenvolve-se com a orientação de reforçar as instituições que se visualizam com capacidade estruturante dos sistemas de saúde, de promover maior liderança na condução setorial ede assegurar o aproveitamento desses recursos, inclusive transnacionais, pelos servidores de todos os países da região. Entende-se como instituições estruturantes dos sistemas de saúde aquelas que têm: capacidade de operacionalizar sistemas e serviços de saúde de maneira efetiva, eficientee sustentável, em especial através do seu poder oficial; capacidade de gestão e de prestação de serviços de saúde (M inistérios da Saúde, por exemplo); e aptidão de treinamento de profissionais de saúde e geração de dados úteis para a tomada de decisão, através de $P \& D$ e do treinamento dos recursos humanos essenciais para o campo da saúde (institutos nacionais de saúde, escolas de saúde pública, escolas técnicas de saúde, outros 
institutos e escolas de graduação em saúde, por exemplo).

Esta programação foi aprovada pelo ConseIho de M inistros de Saúde da Unasul, em sua reunião de novembro de 2009, realizada em Guayaquil, Equador, e corroborada por resoluções do Conselho, em sua reunião de Cuenca (abril de 2010).

\section{Redes de Instituições Estruturantes} dos Sistemas de Saúde

Entre os mecanismos que visam ao desenvolvimento de capacidade técnica e gestão dos recursos humanos em saúde, destaca-se a promoção de maior articulação entre as instituições que formam pessoal científico, técnico e administrativo nos diversos países através do estabelecimento de redes especializadas que possam facilitar a interação entre elas, potencializar seu desempenho einfluenciar o desenvolvimento de um modelo de atenção universal, equitativo e de qualidade (Quadros 4 e 5).

Outra dimensão fundamental da Rede é o fomento ao desenvolvimento de pesquisas entre as instituições-membros na interface das áreas de Saúde, Educação e Trabalho, que permita ampliar e fortalecer suas atividades de ensino e cooperação técnica.

As redes de Escolas Profissionais focalizarão prioritariamente, mas não exclusivamente, a medicina, a enfermagem ea odontologia, profis-

Quadro 4. O peracionalização do desenvolvimento e gestão de recursos humanos em saúde.

- Priorizar a interação entre as instituições estruturantes em que se desenvolve a formação de pessoal com o objetivo de que apoiem a transformação dos sistemas de saúde;

- Apoiar todos os países da Unasul no fortalecimento das capacidades nacionais e sub-regionais para a condução, formulação, implementação e avaliação de políticas e planos de longo prazo que respondam aos desafios críticos em recursos humanos em saúde e às necessi dades de desenvolvimento de recursos humanos identificados nos outros quatro componentes da Agenda de Saúde, mediante a criação do Instituto Sul-Americano de Governo em Saúde (ISAGS); e

- Facilitar a implementação de todos os componentes da Agenda de Saúde da Unasul mediante a criação de um Programa de Bolsas U nasul-Saúde, como estratégia para responder às necessidades formativas, de pesquisa e outros aspectos identificados no desenvolvimento de recursos humanos.

Quadro 5. Iniciativas para constituição das Redes de Instituições Estruturantes.

Rede de Institutos Nacionais de Saúde da América do SUL (RINS/U nasul) ${ }^{31}$ - criada em março de 2010 em Lima, Peru, em reunião real que estabeleceu as bases de seu funcionamento. Seu Plano Quinquenal 2010-2015 aprovado em outubro de 2010 inclui atividades de cooperação em pesquisa e desenvolvimento, ensino e prestação de serviços de referência, assim como medidas de fortalecimento da rede e de cada instituto nacional, para o apoio às prioridades da Unasul-Saúde definidas no seu Plano Quinquenal. O Instituto Nacional de Saúde do Peru é a instituição coordenadora da RINS/Unasul.

Rede de Escolas Técnicas da Unasul-Saúde ${ }^{32}$ - criada em dezembro de 2009 no Rio de Janeiro, com coordenação a cargo da Escola Politécnica da Saúde Joaquim Venâncio, da Fundação Oswaldo Cruz, Brasil. Entre os principais objetivos, a Rede tratará de elaborar marcos comum de formação e currículos de referência, de acordo com áreas prioritárias identificadas para a formação de técnicos na região ( vigilância em saúde; enfermagem; e informação e registros em saúde); produzir e intercambiar materiais didáticos de acordo com os marcos comuns de formação, com os currículos de referência e com as áreas prioritárias identificadas; compartilhar as experiências de superação e/ou profissionalização para empíricos, auxiliares e técnicos com experiência e recém-egressos em articulação com as instituições formadoras, as associações profissionais de técnicos e outros atores do mundo do trabalho; e elaborar projeto conjunto para a formação de docentes para a área de formação de técnicos em saúde.

Rede de Escolas Nacionais de Saúde Pública da Unasul-Saúde - criada em março de 2011, em Assunção, Paraguai, é coordenada pelo Instituto Nacional de Saúde do Paraguai e sua secretaria executiva localiza-se na Escola Nacional de Saúde Pública do Brasil. A Rede prepara seu plano de trabalho quinquenal e seguirá uma orientação "escola de governo em saúde", para atender às necessidades de qualificação do quadro de dirigentes dos M inistérios da Saúde da região e a produção de conhecimento inovador em sistemas e serviços de saúde, em estreita cooperação com o ISAGS. 
sões que mais diretamente cobrem a atenção primária de saúde. Elas teriam como foco três possíveis áreas de atuação: (1) reorientação da formação básica, com ênfase na atenção primária de saúde; (2) implementação de programas de educação permanente; e (3) desenvolvimento de especializações em áreas prioritárias. Esses três componentes vêm sendo desenvolvidos no Brasil pelo M inistério da Saúde, com os programas do Pró-Saúde (orientado à atenção primaria), UNASUS (Universidade do SUS), para educação permanente, ea seleção de residências para especialização em áreas prioritárias; a proposta é que taisiniciativas venham a apoiar ou interatuar com programas semelhantes nos demais países.

Essas redes passam a integrar o acervo da Unasul-Saúde, com grande potencial de contribuições à formação de recursos humanos, à pesquisa eao desenvolvimento tecnológico eà prestação de serviços de referência na região.

Instituto Sul-Americano

de Governo em Saúde (ISAGS)

O Governo do Brasil sugeriu e propôs-se a assumir a responsabilidade de facilitador da constituição do Instituto Sul-Americano de Governo em Saúde(ISAGS), por meio daFundação O swaldo Cruz, com o apoio dos M inistérios da Saúde e das Relações Exteriores. N este projeto aproveita-se a experiência da Fiocruz, acumulada desde 1988 com a Escola de Governo em Saúdeea Rede de Escolas de Governo do Brasil, que implicou substancial reorientação dos programas de pesquisa em política e gestão e de formação avançada de recursos humanos para a expansão da capacidade e qualidade do SUS.

O ISAGS é instituição pública de natureza comunitária (pertencente a todos os países signatários da Unasul), com sede no Rio de Janeiro, devendo contar com pequeno corpo de condução docente e técnico, que se complementa com especialistas em áreas específicas por períodos temporários de acordo com a programação que venha a ser estabelecida.

0 Instituto tem como função principal a gestão do conhecimento para o fortalecimento das capacidades nacionais de condução dos sistemas de saúde, incluindo recompilação e sistematização de conhecimentos relevantes existentes, produção de novos conhecimentos (como teoria ou como inovação) e sua utilização nos âmbitos respectivos. A poia, igualmente, a condução da integração sul-americana na área da saúde, a governança regional e o estudo e seguimento das polí- ticas sociais regionais, com ênfases em diplomacia e saúde internacional, assim como na análise dos determinantes internacionais da saúde que incidem sobre os países e a Unasul, contribuindo para a construção de um possível sistema sulamericano de saúde.

Constitui-se em espaço de análise permanente do impacto das políticas de saúde, incluindo a eficácia dos modelos de atenção implementados e dos recortes a partir dos quais se organizam os programas de saúde, o rol das tecnologias e os novos desafios que se apresentam na organização daredede serviços desaúde. Dialoga com as experiências acumuladas por outros centros regionais (como Ilpes, Celade e outros) e deverá interagir com as escolas de pós-graduação no campo da saúde pública e áreas correlatas (meio ambiente, saneamento, proteção social, educação), aplicando no âmbito da capacitação diversos mecanismos docentes presenciais, a distância, itinerantese recursos tecnológicos os mais variados.

Os participantes de seus programas de capacitação serão altos funcionários ou profissionais com esse potencial, indicados pelos M inistérios da Saúde, da área de saúde e afins.

\section{Programa de Bolsas Unasul-Saúde}

0 estabelecimento de um programa de bolsas da Unasul repousa no fato de que, apesar dos progressos realizados no desenvolvimento de recursos humanos em saúde na América do Sul, tanto na quantidade quanto na melhora da qualidade das instituições formadoras, ainda falta pessoal qualificado. Isso é evidente no campo da saúde pública e da gestão em saúde, assim como em áreas especializadas da atenção à saúde, tais como saúde da mulher e da criança, doenças infecciosas e oncologia.

O Programa de Bolsas facilitará a formação de recursos humanos em áreas críticas da Agenda de Saúde da Unasul einiciará com uma oferta de cem bolsas anuais. Serão priorizados candidatos vinculados às instituições públicas dos países preferenciais; desta forma, as bolsas servirão como um mecanismo de superação das assime trias no interior da Unasul.

O financiamento do programa será realizado com os mesmos recursos no caso dos países quejá apoiam estudantes estrangeiros; naqueles países onde isso não ocorra, a Unasul buscará recursos de doadores internacionais a serem identificados. 


\section{Discussão econclusões}

A Unasul-Saúdeéum arranjo intergovernamental que vem evoluindo como um excelente exemplo de "diplomacia da saúde" ${ }^{3,34}$ e de "cooperação Sul-Sul" 35,36 que os M inistérios da Saúde e das Relações Exteriores dos países da América do Sul estão desenvolvendo. As iniciativas em saúde descritas no contexto da Unasul estabelecem um novo marco para a diplomacia regional, passando a orientar o diálogo e as condições do intercâmbio e das modalidades de cooperação. A retórica política passa a ser acompanhada por ações concretas, desenvolvidas não apenas através de acordos bilaterais, como também por iniciativas multilaterais, em que os países interagem aportando e recebendo cooperação respectivamenteem áreas mais desenvolvidas e demaior necessidadeem cada um deles. Trata-se de um processo de "diplomacia da saúde" sul-americano, coerente com as características mais amplas da integração regional, que supõe principalmente a superação das assimetrias entre os países e a ação internacional conjunta.

A cooperação regional na área da saúde assume importância especial, tendo em vista a maior identidade política ea similaridade da problemática a ser tratada, fatores que potencializam os possíveis resultados da cooperação horizontal. Em especial a concepção das redes deinstituições estruturantes a serem coordenadas cada uma por diferentes países já se constitui em estratégia de ampla participação regional, assim como o mecanismo de promoção de lideranças para a melhoria da governança em saúde, cujas ações al cançarão o conjunto e cada um dos países da região.

O Plano Quinquenal 2010-2015 da UnasulSaúde, aprovado pelos Ministros de Estado da Saúde, dá bases políticas e técnicas à cooperação entre os países, pois se baseia nos princípios de respeito à autonomia dos países, alinhamento, apropriação e harmonização. Por meio dele, 0 bloco político sul-americano se projeta em diversas dimensões, já assinaladas, como também na ação internacional conjunta.

Além de ações decisivas da Unasul na resolução de conflitos políticos regionais, casos da ameaça de golpe na Bolívia, em 2008, e no recente conflito Colômbia-Venezuela, também a UnasulSaúde têm demonstrado que pode ser um espaço de convergência e harmonização política. Além disso, já deu mostras de sua importância também no terreno da atuação conjunta dos países no cenário internacional, por ocasião da Assembleia Mundial da Saúde de 2010, realizada pela OM S, em Genebra, quando os representantes da América do Sul articularam suas posições em diversas matérias sensíveis, como a falsificação de medicamentos e no caso das patentes de medicamentos e suas implicações sobre a saúde pública.

Embora não desconhecendo as assimetrias existentes entre os países sul-americanos, admite-se que a orientação política materializada no Plano Quinquenal 2010-2015 da Unasul-Saúde representa importantecontribuição para uma integração baseada em princípios de solidariedade e complementaridade, que certamente potencializará o desenvolvimento da região e colaborará para a mel horia nas condições de vida e saúde dos sul-americanos.

\section{Colaboradores}

PM Buss e JR Ferreira participaram igualmente de todas as etapas de elaboração do artigo. 


\section{Referências}

1. Costa D. América do Sul: um novo espaço em construção. In: II Conferência Nacional de Política Externa e Política Internacional - 0 Brasil e o mundo que vem aí. Braślia: Fundação Alexandre de Gusmão; 2007.

2. Simões AJF. Unasul: a América do Sul e a construção de um mundo multipolar. In: IV Conferência Nacional de Política Externa e Política Internacional: textos acadêmicos. Brasília: Fundação Alexandre de Gusmão; 2009.

3. Constituição Federal de 1988, artigo $4^{\circ}$, parágrafo único. [acessado 2010 jan 12]. Disponível em: http:// www.planalto.gov.br/ccivil_03/constituicao/constitui $\%$ C3\%A7ao.htm

4. Santos E. América do Sul. In: IV Conferência Nacional de Política Externa e Política Internacional: textos acadêmicos. Brasília: Fundação Alexandre de Gusmão; 2009.

5. Pinheiro Guimarães S. Desafios brasileiros na era dos gigantes. Rio de Janeiro: Contraponto; 2005.

6. União das Nações Sul-Americanas (Unasul). Tratado Constitutivo da União de Nações Sul-Americanas. [acessado 2010 jan 12]. Disponível em: http:// www.itamaraty.gov.br/sala-de-imprensa/notas-aimprensa/2008/05/23/tratado-constitutivo-da-uniaode-nacoes-sul/?searchterm=constituição-unasul

7. Rivarola M. Latinoamérica, identidad e integración: integração da América do Sul - textos acadêmicos. v. II. Brasília: Fundação Alexandre de Gusmão; 2009.

8. Bava SC. Gigante pela própria natureza. Le M onde Diplomatique Brasil 2009; 19:3.

9. Buss PM. A Unasul-Saúde. Le M onde Diplomatique Brasil 2009; 26:30-31.

10. Oualalou L. Brasília oublie le "complexe du chien bâtard". Le M onde Diplomatique 2010; 670:17.

11. Silva MAM, M elo BM. Soja: a expansão dos negócios. Le M onde Diplomatique Brasil 2009; 19:4-5.

12. Tautz C. Da Alca à IIRSA. Le M onde Diplomatique Brasil 2009; 19:7-8.

13. Gonzales GT. Pressão pela força. Le M onde Diplomatique Brasil 2009; 19:6-7.

14. Cassen B. Resposta ao liberalismo. Le M onde Diplomatique Brasil 2009; 19:9.

15. Carvalho CE. Passos importantes, muitas dificuldades. Le M onde Diplomatique Brasil 2009; 19:10-11.

16. Amorim C. Por uma nova arquitetura internacional. Palestra do Ministro Celso Amorim como convidado de honra do Seminário Diplomático do Ministério dos Negócios Estrangeiros de Portugal. Lisboa, 5 jan. 2009.

17. Oras-Conhu. Plano Sub-regional de Saúde da Região Andina. [acessado 2010 mar. 22]. Disponível em: http//www.orasconhu.org
18. M ercosul Saúde. [acessado 2010 jan 12]. Disponível em: http://www.mercosulsaudedevsite.com.br, acessado em 22/03/2010

19. Organização do Tratado de Cooperação Amazônica (OTCA). [acessado 2010 mar 22]. Disponível em: http://www.otca.org.br

20. Amorim C. Entrevista à Cooperação Saúde. Boletim da atuação internacional brasileira em saúde. [acessado 2011 mar 10]. Disponível em: http://portal. saude.gov.br/portal/arquivos/pdf/boletim_aisa_ final.pdf.

21. Sistema Econômico Latinoamericano (SELA). Experiencias de cooperación en el sector de la salud en América Latina y el Caribe: balance crítico y propuestas de acción de alcance regional. Caracas: SELA, SP/ RRC-ICSALC/DT n 2-10; 2010.

22. Organização Pan-Americana da Saúde (O pas). Oficina de Chile. Salud en Sudamérica 2008. Documento de Análisis de Situación - PWR CHI/09/HA/01). Santiago, Chile: Organização Pan-Americana da Saúde; 2009. [acessado 2010 jan 12]. Disponível em: http:// new.paho.org/chi/images/PDFs/salud en sudamerica_2008.pdf

23. União de Nações Sul-Americanas (Unasul). Saúde. Plano Quinquenal 2010-2015. [acessado 2010 fev 2]. Disponível em: http://www.unasursalud.org/images/ stories/documentos/plan_quinquenal_ingles.pdf

24. Gadelha CAG. Desenvolvimento, complexo industrial da saúde e política industrial. Rev Saude Publica [periódico na Internet]. 2006 [acessado 2009 jul 26]; 40(N.Esp):11-23. Disponível em: www.scielosp.org/ $\mathrm{pdf} / \mathrm{rsp} / \mathrm{v} 40 \mathrm{nspe} / 30617 . \mathrm{pdf}$

25. Word Health Organization (WHO). Commission on Social Determinants of $\mathrm{H}$ ealth. Closing the gap in a generation. [acessado 2010 jan 22]. Disponível em: http//www. who.int/socialdeterminants/the commission/final_report/en

26. Comissão Nacionāl sobre Determinantes Sociais da Saúde (CNDSS). As causas das iniquidades em saúde no Brasil - Informe final da CNDSS. [documento na Internet] [acessado 2010 jan 22]. Disponível em: http://determinantes.saude.bvs.br/php/index.php

27. OPS-Health Canada. Chamado à Ação de Toronto para uma Década de Recursos Humanos em Saúde (2006-2016). [acessado 2010 mar 25]. Disponível em: http://bvsms-bases.saude.bvs.br/cgi-bin/wxis.exe/ iah/ms

28. Pan American Health Organization (PAHO). Health Agenda for the Americas. Washington, DC: PAHO; 2007.

29. OPS. 27ạ Conferência Sanitária Pan-Americana. $M$ etas regionais em matéria de recursos humanos para a saúde (2007-2015). Washington, DC: OPS; 2007. 
30. ORAS-CONHU. Plan Andino de Recursos Humanos en Salud. [acessado 2010 jan 12]. Disponível em: http://www.orasconhu.org/index.php?IDIOM A =SP $\&$ plantilla $=$ contenido\&ncategorial $=31$

31. Rede de Institutos Nacionais de Saúde (RINS). União de Nações Sul-Americanas (U nasul). [site na Internet]. [acessado 2010 maio 12]. Disponível em: http:/ /www.ins.gob.pe/portal

32. Rede Internacional de Escolas Técnicas de Saúde (RETS). União de Nações Sul-Americanas (U nasul) [acessado 2010 maio 12]. Disponível em: http:// www.rets.epsjv.fiocruz.br/home.php?Area $=$ N oticia $\& \mathrm{Num}=104$

33. Kickbusch I, Silberschmidt G, Buss PM. Global health diplomacy: the need for new perspectives, strategic approaches and skills in global health. Bulletin of theWorld Health Organization 2007; 85(3): 230-232.

34. Kickbusch I, Berger C. Diplomacia da saúde global. Rev Eletrônica de Comunicação, Informação \& Inovação em Saúde (RECIIS) 2010; 4(1):19-24.

35. Buss PM, Ferreira JR. Ensaio crítico sobre a cooperação internacional em saúde. $R$ Eletr de Com Inf Inov Saúde (RECIIS) 2010; 4(1):46-58.

36. Buss PM, Ferreira JR. Diplomacia da saúde e cooperação Sul-Sul: as experiências da Unasul-Saúde e do Plano Estratégico de Cooperação em Saúde da Comunidade de Países de Língua Portuguesa (CPLP). R Eletr de Com Inf Inov Saúde. (RECIIS) 2010; 4(1):81-93.

Artigo apresentado em 08/08/2010

Aprovado em 08/12/2010

Versão final apresentada em 24/03/2011 